Oslo. The cardiovascular disease study in Norwegian counties. Results from second screening. Oslo: National Health Screening Service, 1988.

14 Freedman DS, Gruchow HW, Anderson AJ, Rimm AA, Barboriak J Relation of triglyceride levels to coronary artery disease: the Milwaukee cardiovar

15 Stensvold I, Urdal P, Thürmer H, Tverdal A, Lund-Larsen PG, Foss OP. High-density lipoprotein cholesterol and coronary, cardiovascular and al cause mortality among middle-aged Norwegian men and women. Eur Heart I 1992;13:1155-63.

16 Costongs GMPJ, Janson PCW, Bas BM. Short-term and long-term intraindividual variations and critical differences of clinical chemical laboratory parameters. 7 Clin Chem Clin Biochem 1985;23:7-16.

17 Hamsten A. Coagulation factors and hyperlipidaemia. Current Opinion in Lipidology 1991;2:26-71.

18 Folsom AR, Wu KK, Davis CE, Conlan MG, Sorlie PD, Szklo M. Population correlates of plasma fibrinogen and factor VII, putative cardiovascular risk factors. Atherosclerosis 1991;91:191-205.

19 Austin MA, Krauss RM. Genetic control of low-density-lipoprotein subclasses Lancet 1986;ii:592-5.

20 Gianturco SH, Bradley WA. Triglyceride-rich lipoproteins and their role in atherogenesis. Current Opinion in Lipidology 1991;2:324-8.

21 Kashyap ML. Clinical utility and methods for assessing triglyceride-rich lipoprotein metabolism. Current Opinion in Lipidology 1991;2:379-84.

22 Reaven GM. Role of insulin resistance in human disease. Diabetes 1988;37: 1595-607.

23 Fontbonne A. Insulin. A sex hormone for cardiovascular risk? Circulation $1991 ; 84: 1442-4$

(Accepted 8 September 1993)

\title{
Cost effectiveness analysis of early zidovudine treatment of HIV infected patients
}

\author{
Eugene Z Oddone, Patricia Cowper, John D Hamilton, David B Matchar, Pamela Hartigan, \\ Greg Samsa, Michael Simberkoff, John R Feussner
}

Center for Health Services Research in Primary Care, Veterans Affairs Medical Center, Durham, NC 27705, USA

Eugene Z Oddone, assistant professor in medicine Patricia Cowper, senior research scientist Greg Samsa, senior research scientist

\section{Research Center on} Acquired

Immunodeficiency Syndrome and HIV Infection, Veterans Affairs Medical Center, Durham, NC

John D Hamilton, chief

Center for Health Policy Research and Education, Duke University, Durham, NC 27710, USA

David B Matchar, director

\section{Veterans Affairs}

Cooperative Studies,

West Haven, CT 06516,

USA

Pamela Hartigan, study

biostatistician

\section{Division of Infectious}

Diseases, Veterans Affairs

Medical Center, New York, NY 10032, USA

Michael Simberkoff, chief

Division of General Internal Medicine, Duke University Medical Center, Durham, NC 27710, USA

John R Feussner, chief

Correspondence to: Dr Oddone.

\section{Abstract}

Objective-To compare cost effectiveness of early and later treeatment with zidovudine for patients infected with HIV.

Design-Markov chain analysis of cost effectiveness based on results of use of health care and efficacy from a trial of zidovudine treatment.

Setting-Seven Veterans Affairs medical centres in the United States.

Subjects-338 patients with symptomatic HIV infection and a lymphocyte count of $200 \times 10^{6}$ to $500 \times 10^{6} \mathrm{CD} 4$ cells $/$.

Interventions-Zidovudine $1500 \mathrm{mg} / \mathrm{day}$ started either at recruitment to the trial or when CD4 cell count fell below $200 \times 10^{\circ} / 1$.

Main outcome measures-Health care costs and rates of disease progression between six clinical states of HIV infection.

Results-Patients given early treatment with zidovudine remained without AIDS for an extra two months at a cost of $\$ 10750$ for each extra month without AIDS (at 1991 costs). Cost effectiveness ratio was most sensitive to the cost of zidovudine and to the quality of life of patients receiving early treatment. At treatment of $500 \mathrm{mg} / \mathrm{day}$ the cost effectiveness ratio for early treatment was $\$ 5432$ for each extra month without AIDS. Patients given early treatment experienced more side effects, and if their quality of life was devalued by $8 \%$ compared with patients treated later the two treatments were equivalent in terms of quality adjusted months of life without AIDS.

Conclusions-Early treatment with zidovudine is expensive and is very sensitive to the cost of zidovudine and to potential reductions in quality of life of patients who experience side effects. Doctors should reconsider early treatment with zidovudine for patients who experience side effects that substantially compromise their quality of life.

\section{Introduction}

Treatment with zidovudine has been shown to prolong survival in patients with newly diagnosed AIDS or advanced AIDS related complex. ${ }^{1}$ At this stage of HIV infection zidovudine is so effective that a doctor need only treat eight patients to prevent one death after six months of treatment. There is, however, much controversy over the efficacy of zidovudine when it is prescribed earlier in the course of HIV infection. Three randomised trials have documented delayed progression to AIDS for patients receiving zidovudine early compared with placebo ${ }^{23}$ or with zidovudine given later but still before development of AIDS. ${ }^{4}$ The Concorde trial, the largest and most recent, reported no delay in progression to AIDS for patients treated early in their infection. ${ }^{5}$ None of the published controlled trials have documented additional survival benefit when zidovudine is given before diagnosis of AIDS.

In spite of this, the current recommended medical practice is to prescribe zidovudine for patients with symptomatic HIV whose lymphocyte counts are below $500 \times 10^{6} \mathrm{CD} 4$ cells $/ 1 .^{6}$ However, the cost implications of giving zidovudine early in HIV infection have not been fully explored. We examined the cost effectiveness of early treatment with zidovudine using data recorded in a Veterans Affairs cooperative study.

\section{Methods}

Data sources-The Veterans Affairs cooperative study (number 298) was a four year, multicentre, randomised, double blind trial that compared early and later treatments with zidovudine for patients with symptomatic HIV infection and lymphocyte counts of $200 \times 10^{6}$ to $500 \times 10^{6} \mathrm{CD} 4$ cells $/{ }^{4}$ Patients were randomised to receive zidovudine $(1500 \mathrm{mg} /$ day $)$ either at enrolment into the study (early treatment) or when their CD4 cell count fell below $200 \times 10^{6} / 1$ (later treatment). Patients were enrolled from January 1987 to January 1990 and were followed up until January 1991. The trial showed that patients given zidovudine early in their infection experienced a delay in the development of AIDS but no improvement in overall survival. This trial was the only one of its kind to keep detailed records of the use of health care by all patients.

Markov decision model - In order to accurately model risk of progression of HIV infection and associated health care costs over an extended period and to perform sensitivity analyses for important cost variables we employed a Markov chain analysis. ${ }^{7}$ We defined six clinically relevant and mutually exclusive states of HIV infection; mildly symptomatic with a CD4 cell count of $200 \times 10^{6}$ to $500 \times 10^{6} / 1$ (state 1); mildly symptomatic with a CD4 count under $200 \times 10^{6} / 1$ (state 2); Pneumocystis carinii pneumonia being the first AIDS defining diagnosis (state 3); a different first AIDS defining diagnosis (state 4); two or more AIDS defining diagnoses (state 5); and death (state 6). The patients' progression through the clinical states was divided into cycles of 60 days. All the patients began in state 1 , and during each subsequent cycle they could either remain in their current state or progress to another state. Patients changed from their current state to any state of greater severity except that 
patients in state 3 could not move to state 4 and patients in state 2 could move back to state 1 . Transition probabilities between clinical states, calculated separately for each treatment group, were determined from the actual rates of disease progression for the patients in the study. The time independent assumption of this Markov chain accurately represented the observed survival and progression to AIDS recorded in the four year study.

Resource use and cost calculations-We separated resource use into four components: inpatient care, outpatient care (including laboratory and diagnostic tests), outpatient drugs except zidovudine, and zidovudine. Rates of resource use were calculated for each treatment group and each disease state based on a patient's state at the end of a cycle. To maximise cost homogeneity for each clinical state, rates were stratified according to whether or not hospitalisation occurred during each cycle. All costs were calculated from the perspective of the health care system. Indirect costs such as lost earnings due to poor health were not estimated. These costs were likely to be correlated with direct health care costs, and indirect costs not related to health (for example, lost earnings due to job market inequities) were likely to be similar for the two treatment groups. Thus, the overall bias due to exclusion of indirect costs is conservative (that is, to overestimate the cost effectiveness of zidovudine). Cost of inpatient care was based on the days spent in a hospital department (medicine, medical intensive care, surgery, surgical intensive care, or psychiatry) multiplied by the average total cost of staying in that department. $^{8}$

Cost of outpatient services was based on the number of visits in each of five categories (medical or surgical clinic visits, psychiatric clinic visits, ancillary clinic visits, diagnostic tests, and procedures) and the average cost of visits in each category. Laboratory tests reported in the study were included in the cost analysis except for tests predetermined by the study protocol (for example, levels of p24 antigens and HIV cultures). Costs of outpatient drugs were based on the average cost of drugs per patient per cycle. Costs of zidovudine per patient per cycle were based on the prescribed dose in the protocol and the average prescription cost $(\$ 1.20$ for $100 \mathrm{mg}$ ). Costs were linked to the disease states based on the cycle during which the service was provided and the disease state of the patient at the end of the cycle. All cost calculations were based on 1991 prices.

Cost effectiveness ratio-All data on efficacy and cost were analysed on an intention to treat basis. Since patients given early zidovudine treatment had no additional survival benefit the unit of effectiveness was months without AIDS. The marginal cost effectiveness of early zidovudine treatment was calculated as the difference between the total costs (costs of drugs and health care) of early and late treatments divided by the difference between the months without AIDS associated with early and later treatments. All health care costs and efficacy data were discounted at an annual rate of $5 \% .^{9}$

\section{Results}

TRANSITIONS TO AIDS

The Markov model was run for four years ( 24 cycles) to correspond to the time of follow up in the study. After four years most of the patients were still without AIDS (in states 1 or 2 of HIV infection) (table I). Patients were more likely to remain in these states if they were given early zidovudine treatment: $64 \%$ of patients given early treatment were alive and without AIDS compared with $56 \%$ of patients given later treatment. Combination of the times spent in states 1 and 2 gave the length of time without AIDS (not discounted) as 39.9 months for the group given early treatment and 38.0 months for the group given later treatment (table I). The results generated by the Markov model were similar to the observed results generated by a life table analysis of trial data (fig 1). This shows that the assumptions of the Markov model used to calculate efficacy were generally satisfied during follow up.

TABLE I-Markov generated model of survival experience after four years (years not discounted) of patients infected with HIV who were given early or late treatment with zidovudine

\begin{tabular}{lccccc}
\hline & \multicolumn{2}{c}{$\begin{array}{c}\text { Expected time in each } \\
\text { disease state (months) }\end{array}$} & & \multicolumn{2}{c}{$\begin{array}{c}\text { Probability of being in each } \\
\text { disease state (\%) }\end{array}$} \\
\cline { 2 - 3 } \cline { 5 - 6 } $\begin{array}{l}\text { State of } \\
\text { HIV }\end{array}$ & $\begin{array}{c}\text { Early } \\
\text { infection }\end{array}$ & $\begin{array}{c}\text { Late } \\
\text { treatment }\end{array}$ & & $\begin{array}{c}\text { Early } \\
\text { treatment }\end{array}$ & $\begin{array}{c}\text { Late } \\
\text { treatment }\end{array}$ \\
\hline 1 & 34.3 & 28.5 & & 50 & 38 \\
2 & 6.6 & 9.5 & & 14 & 18 \\
3 & 0.8 & 1.6 & & 2 & 5 \\
4 & 2.3 & 3.7 & & 7 & 11 \\
5 & 0.8 & 1.3 & & 3 & 5 \\
6 & NA & NA & & 24 & 23 \\
\hline
\end{tabular}

NA=not applicable. $\quad$ `See text for details.

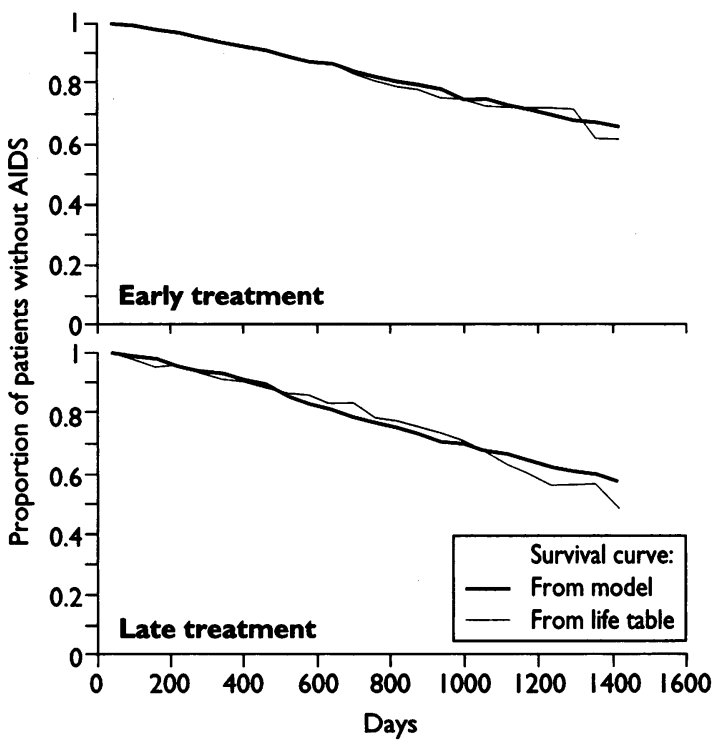

FIG 1-Survival curves for HIV infected patients' progression to AIDS after early or late treatments with zidovudine. Curves generated by Markov model or by life table analysis of trial data

\section{costs}

Table II summarises the distribution of costs for hospital inpatient health care. For states 2, 3, and 5 of HIV infection inpatient costs were higher for patients given early treatment, while for states 4 and 6 inpatient costs were slightly higher for patients given later treatment. While outpatient costs accounted for a smaller proportion of total health care costs, they were consistently higher for the patients given early treatment. Average outpatient costs per cycle were $\$ 65-\$ 1128$ depending on disease state.

Total expected health care costs over four years for the group given early treatment were $\$ 55193$, compared with $\$ 36918$ for the group given later treatment (table III). All recorded health care costs were higher for patients given early treatment. Inpatient costs were $15 \%$ higher with a difference of $\$ 3191$ and outpatient costs were $19 \%$ higher with a difference of $\$ 1523$. Costs of zidovudine were almost threefold higher. The marginal cost effectiveness ratio of early zidovudine treatment was $\$ 10750$ per extra month of life without AIDS. While the patients given early treatment did not on average survive an extra year without AIDS the annual equivalent was about $\$ 129000$ per year of life without AIDS. 


\begin{tabular}{|c|c|c|c|c|c|c|c|c|c|}
\hline \multirow{2}{*}{$\begin{array}{l}\text { State of HIV } \\
\text { infection at end } \\
\text { of cycle }{ }^{\star}\end{array}$} & \multirow{2}{*}{$\begin{array}{l}\text { No (\%) of } \\
\text { patients in } \\
\text { hospital }\end{array}$} & \multirow{2}{*}{$\begin{array}{c}\text { Probability of } \\
\text { hospitalisation } \\
\text { in a cycle }(\%)\end{array}$} & \multirow{2}{*}{$\begin{array}{c}\text { Mean } \\
\text { (interquartile } \\
\text { range) length of } \\
\text { stay (days) }\end{array}$} & \multicolumn{4}{|c|}{ Mean $\%$ of length of stay in each ward } & \multirow{2}{*}{$\begin{array}{l}\text { Weighted } \\
\text { cost per } \\
\text { day }(\$)\end{array}$} & \multirow{2}{*}{$\begin{array}{l}\text { Hospital } \\
\text { cost per } \\
\text { cycle }(\$) \dagger\end{array}$} \\
\hline & & & & Medical & Surgical & $\begin{array}{l}\text { Intensive } \\
\text { care }\end{array}$ & Psychiatric & & \\
\hline \multicolumn{10}{|c|}{ Early zidovudine treatment } \\
\hline 1 & $92(56)$ & 13 & $8.9(2-11)$ & 74 & 8 & 0 & 18 & 567 & 656 \\
\hline 2 & $28(48)$ & 19 & $14 \cdot 6(3-13)$ & 86 & 9 & 0 & 5 & 607 & 1639 \\
\hline 3 & $9(100)$ & 62 & $19 \cdot 2(9-22)$ & 92 & 7 & 1 & 0 & 632 & 7523 \\
\hline 4 & $11(69)$ & 27 & $10.9(3-14)$ & 74 & 9 & 0 & 17 & 570 & 1676 \\
\hline 5 & $9(100)$ & 70 & $18 \cdot 6(5-21)$ & 99 & 0 & 1 & 0 & 633 & 8242 \\
\hline 6 & $11(48)$ & 48 & $13.5(5-18)$ & 79 & 9 & 12 & 0 & 697 & 4517 \\
\hline \multicolumn{10}{|c|}{ Late zidovudine treatment } \\
\hline 1 & $83(54)$ & 10 & $10.6(2-13)$ & 71 & 7 & 0 & 22 & 555 & 588 \\
\hline 2 & 37 (42) & 16 & $7 \cdot 2(2.9)$ & 85 & 10 & 1 & 4 & 616 & 710 \\
\hline 3 & $9(82)$ & 24 & $18 \cdot 4(15-22)$ & 85 & 0 & 3 & 12 & 608 & 2685 \\
\hline 4 & $14(52)$ & 24 & $14 \cdot 6(5-21)$ & 78 & 14 & 1 & 7 & 604 & 2116 \\
\hline 5 & $10(71)$ & 41 & $26 \cdot 2(15-31)$ & 100 & 0 & 0 & 0 & 627 & 6735 \\
\hline 6 & $13(65)$ & 65 & $12.5(6-21)$ & 100 & 0 & 0 & 0 & 627 & 5094 \\
\hline
\end{tabular}

rails.

†Calculated as probability of hospitalisation $\times$ mean length of stay $\times$ weighted cost per day.

TABLE III-Costs and effects (discounted at annual rate of 5\%) of early or late treatment with zidovudine for patients infected with HIV after four years

\begin{tabular}{lcc}
\hline & Early treatment & Late treatment \\
\hline Costs (\$): & 55193 & 36918 \\
Hospital inpatient (\%) & $24162(44)$ & $20971(57)$ \\
Outpatient (\%) & $9603(17)$ & $8080(22)$ \\
Zidovudine (\%) & $21428(39)$ & $7867(21)$ \\
Effect (months without AIDS) & 36.8 & 35.1 \\
Cost/extra month without AIDS (\$) & 10750 & \\
\hline
\end{tabular}

\section{SENSITIVITY ANALYSES}

The first sensitivity analysis varied the cost of zidovudine. This analysis was particularly important because the current recommended dose of $500 \mathrm{mg} /$ day $^{6}$ is one third that used in the trial $(1500 \mathrm{mg} / \mathrm{day})$. At a dose of $500 \mathrm{mg} /$ day the cost effectiveness ratio for early treatment was $\$ 5432$ per month or about $\$ 65000$ per year of life without AIDS.

In the trial the patients given early zidovudine treatment reported more nausea, vomiting, and diarrhoea while patients given later treatment reported more rashes. ${ }^{4}$ Because the impact of these symptoms on health care costs and the patients' quality of life was unclear and because some of the symptoms in the group given early treatment might have resulted from the higher dose of zidovudine used in the trial we performed two additional sensitivity analyses. Firstly, we reduced the use of health care associated with state 1 of HIV infection in the group given early treatment to the same level observed in the group given later treatment, thereby assuming that all additional costs in the early treatment were attributable to side effects of zidovudine. At a dose of zidovudine $500 \mathrm{mg} /$ day the cost per additional year of life without AIDS was still $\$ 48000$. Secondly, we calculated what decrease in quality of life caused by side effects of early zidovudine treatment would render the two treatments equal in quality adjusted time without AIDS (fig 2). Since the overall difference in efficacy between the two treatments was small only a minor decrease in quality of life (about $8 \%$ ) was necessary to make the two treatments equal in quality adjusted time without AIDS.

\section{Discussion}

The debate over zidovudine treatment for patients with HIV centres on when it should be prescribed. The first randomised controlled trial established the efficacy of zidovudine given to patients with recently diagnosed AIDS. ${ }^{1}$ The next step was to test its efficacy for patients earlier in the course of their infection. Two subsequent trials were stopped because patients given early zidovudine treatment progressed to AIDS later than those who received placebo. ${ }^{23}$ At that time a delay in progression to AIDS was deemed an important clinical endpoint for improving quality of life. It was also assumed that a delay in progression to AIDS would prolong the lives of these patients. This assumption was supported by results from three large observational studies. ${ }^{10-13}$ The two most recent randomised controlled trials compared zidovudine given early with zidovudine given later but still before AIDS. One of the trials reported a small absolute delay in progression to AIDS $^{4}$ while the other did not. ${ }^{5}$ We attempted to extend this investigation by considering not only the efficacy of zidovudine but also the costs associated with early and later treatments.

One strength of our study is that the analysis was based on data collected prospectively rather than on estimates of cost based on usual practice patterns. Also, the trial which generated our data was conducted at six medical centres so that the observed rates of use of health care were unlikely to be overly affected by the patterns of practice at any one hospital and are thus more suitable for generalisation than results from a single site. Similarly, cost calculations based on our data are likely to be representative of costs in other large managed health care systems: the doctors in the six medical centres were salaried and the hospitals operated under global budgeting, thereby minimising incentives for overuse of facilities.

We also varied the value assigned to life without AIDS for patients receiving early treatment. Our analysis indicated that only a small $(8 \%)$ decrease in quality of life due to side effects of zidovudine treatment made the quality adjusted time without AIDS similar to that of patients not taking zidovudine. While the absolute number of side effects did not differ between the treatment groups in the trial, other studies have shown that patients given zidovudine early in the course of HIV infection experience significantly more anaemia needing transfusion, nausea, vomiting, and malaise. ${ }^{14}$ In addition, there is increasing evidence of a substantial decrease in the quality of life of patients as they progress from asymptomatic HIV infection to AIDS. ${ }^{15} 16$ Some studies have shown a drop of more than $30 \%$ in general health and wellbeing for patients who progress to AIDS. ${ }^{15}$ These findings and our analysis suggest that, in addition to higher economic costs of early zidovudine treatment, there is very little margin for side effects caused by early treatment before the additional quality adjusted time without AIDS conferred by the treatment disappears.

In this trial and two previously published trials ${ }^{23}$ the difference between treatment strategies in delaying progression to AIDS was small in absolute terms. If there is no delay in progression to AIDS, as was found in the Concorde trial, then the cost effectiveness ratio would be infinite. This study shows that even if early zidovudine treatment is moderately effective it is not cost effective. The cost effectiveness of early 


\section{Clinical implications}

- Zidovudine significantly improves survival for patients with newly diagnosed AIDS

- For patients earlier in their course of HIV infection, zidovudine confers no survival advantage and only a small advantage in delayed progression to AIDS

- At the currently recommended dose of zidovudine, early treatment costs an extra $\$ 5432$ per additional month of life without AIDS relative to treatment later in the course of infection

- This study shows that such early zidovudine treatment is very costly relative to the benefit conferred

zidovudine treatment for patients with HIV infection cannot be compared directly with other medical interventions because the unit of effectiveness in most other cost effectiveness analyses is years of life saved. However, we estimated that early zidovudine treatment ( $500 \mathrm{mg} /$ day) cost $\$ 65000$ for each year of life without AIDS. Schulman et al reported a cost of $\$ 70526$ per year of life saved for early treatment with zidovudine $\left(500 \mathrm{mg} /\right.$ day). ${ }^{17}$ Their analysis differed from ours because they assumed prolonged survival for patients with delayed progression to AIDS although there is no evidence from clinical trials to support this assumption. We could not calculate years of life saved as we did not observe any additional survival benefit conferred to patients given early treatment in this four year trial. Other cost effectiveness ratios of treatments for diseases with high mortalities include $\$ 59922$ per year of life saved for haemodialysis in a renal centre ${ }^{18}$; $\$ 67057$ per year of life saved for liver transplantation for patients with chronic hepatitis ${ }^{19} ; \$ 70302$ per year of life saved for bone marrow transplantation for acute non-lymphocytic leukaemia ${ }^{20}$; and $\$ 7 \mathrm{~m}$ per quality adjusted life year gained for use of prophylactic intravenous immunoglobulin for chronic lymphocytic leukaemia. ${ }^{21}$ (All cost effectiveness ratios have been adjusted to 1991 costs. $^{22}$ )

This study has several potential limitations. Firstly, the analysis was limited to benefits accrued over four years. We addressed this by reporting months of life without AIDS as the observed unit of effectiveness for the cost effectiveness ratios. We did not assume that prolonging the time to development of AIDS would prolong overall survival because no empirical evidence supports such an assumption. Secondly, we did not adjust the cost of zidovudine downward in either treatment group for patients whose dose had to be reduced because of zidovudine toxicity. We did, however, perform sensitivity analyses both on the cost of zidovudine and the differential cost of health care in the late treatment group before the patients were given zidovudine. Even with the assumption that all patients in the early treatment group received zidovudine $500 \mathrm{mg} /$ day and that patients in both groups had equal health care costs before their CD4 cell counts fell below $200 \times 10^{6} / 1$, the cost effectiveness ratio of early treatment was still high: $\$ 48000$ per year of life without AIDS. Lastly, our results are applicable only to early single treatment with zidovudine. Recent combination strategies of zidovudine with didanosine and zalcitabine were not considered, but since these strategies may increase cost of treatment without necessarily improving efficacy the resulting cost effectiveness ratios may well be less favourable than those reported here.

The high cost of zidovudine and the relatively short delay in progression to AIDS mean that early treatment with zidovudine is expensive and does not necessarily confer a survival benefit on treated patients. We conclude that at the current cost of zidovudine early treatment for patients infected with HIV is not cost effective. Furthermore, if patients experience even a small decrease in their quality of life the potential efficacy of early zidovudine treatment is negated.

This study was supported by grants from Veterans Affairs Research and Development, Veterans Affairs Cooperative Studies Program, and EZO was funded by the Veterans Affairs Health Services Career Development Program. We thank Joe Lipscomb for consultation, Michael Monger for computer assistance, and Jeanine Wheless for editorial assistance.

1 Fischl MA, Richmann DD, Grieco MH, Gottlieb MS, Volberding PA, Laskin $\mathrm{OL}$, et al. The efficacy of azidothymidine (ZDV) in the treatment of patients with acquired immunodeficiency syndrome and AIDS-related complex: a double-blind, placebo-controlled trial. N Engl f Med 1987;317:185-91.

2 Volberding PA, Lagakos SW, Koch MA, Pettinelli C, Myers MW, Booth DK, et al. Zidovudine in asymptomatic human immunodeficiency virus infection: a controlled trial in persons with fewer than $500 \mathrm{CD} 4$-positive cells per cubic a controlled trial in persons with fewer than

3 Fischl MA, Richmann DD, Hansen N, Collier AC, Carey JT, Para MF, et al. The safety and efficacy of zidovudine (ZDV) in the treatment of subjects with mildly symptomatic human immunodeficiency virus type 1 (human immunodeficiency virus) infection: a double-blind, placebo-controlled trial. Ann Intern Med 1990;112:727-37.

4 Hamilton JD, Hartigan PM, Simberkoff MS, Day PL, Diamond GR, Dickinson GM, et al. A controlled trial of early versus late treatment with zidovudine in symptomatic human immunodeficiency virus infection. Results of a VA cooperative study. N Engl f Med 1992;326:437-43.

5 Aboulker JP, Swart AM, Concorde Coordinating Committee. Preliminary analysis of the Concorde trial. Lancet 1993;341:890-1.

6 NIH state-of-the-art conference on zidovudine therapy for early human immunodeficiency virus infection. Recommendation for zidovudine: early infection. $尹 A M A$ (in press)

7 Beck JR, Pauker SG. The Markov process in medical prognosis. Med Decis Making 1983;3:419-58.

8 Department of Veterans Affairs. Cost distribution report. Medical care appropriateness. Durham, NC: Veterans Affairs Medical Center, 1991. (RCS 10-0141;.

9 Drummond MF, Stoddart GL, Torrance GW, eds. Methods for the economic evaluation of health care programmes. London: Oxford University Press, 1988:81.

10 Swanson CE, Cooper DA. Factors influencing outcome of treatment with zidovudine of patients with acquired immunodeficiency syndrome in Australia. F Acquir Immune Defic Syndr 1990;4:749-57.

11 Moore RD, Hidalgo J, Sugland BW, Chaisson RE. Zidovudine and the natural history of the acquired immunodeficiency syndrome. $N$ Engl $f$ Med 1991;324:1412-6.

12 Graham NMH, Zeger SL, Park LP, Vermund SH, Detels R, Rinaldo CR, et al. The effects on survival of early treatment of human immunodeficiency te al. The effects on survival of early treatment of

13 Graham NMH, Zeger SL, Park LP, Phair JP, Detels R, Vermund SH, et al. Effect of zidovudine and pneumocystis carinii pneumonia prophylaxis on progression of human immunodeficiency virus-1 infection to acquired immunodeficiency syndrome. Lancet 1991;338:265-9.

14 Koch MA, Volberding PA, Lagakos SW, Booth DK, Tettinelli C, Myers MW, et al. Toxic effects of zidovudine in asymptomatic human immunodeficiency virus-infected individuals with $\mathrm{CD} 4+$ cell counts of $0.5 \times 10^{\circ} / \mathrm{L}$ or less. Arch Intern Med 1992;152:2286-92.

15 Lubeck DP, Fries JF. Health status among persons infected with human immunodeficiency virus. Med Care 1993;31:269-76.

16 Gelber RD, Lenderking WR, Cotton DJ, Cole BF, Fischl MA, Goldhirsch A, et al. Quality-of-life evaluation in a clinical trial of zidovudine therapy in patients with mildly symptomatic HIV infection. Ann Intern Med 1992;116: 961-6.

17 Schulman KA, Lynn LA, Glick HA, Eisenberg JM. Cost-effectiveness of lowdose zidovudine therapy for asymptomatic patients with human immunodose zidovudine therapy for asymptomatic patients with hum

18 Garner TI, Dardis R. Cost-effectiveness analysis of end-stage renal disease treatments. Med Care 1987;25:25-34.

19 Evans RW. Cost-effectiveness analysis of transplantation. Surg Clin Norh Am 1986;66:603-16.

20 Welch HG, Larson EB. Cost-effectiveness of bone marrow transplantation in acute nonlymphocytic leukemia. $N$ Engl F Med 1989;321:807-12.

21 Weeks JC, Tierney MR, Weinstein MC. Cost-effectiveness of prophylactic intravenous immune globulin in chronic lymphocytic leukemia. $N$ Engl f Med 1991;325:81-6.

22 US Department of Commerce, Bureau of Census. Statistical abstracts of US. Washington, DC: GPO, 1992:469. (Medical care component of the consumer price index, table 738 .)

(Accepted 10 September 1993) 